\title{
VALUE OF BIOCHEMICAL URINARY MARKERS IN DIAGNOSIS AND PROGNOSIS OF BLADDER CANCER PATIENTS
}

\author{
Ebtsam R. Zaher ${ }^{(1)}$, Marwa S. Abo Eleneen ${ }^{(1)}$, Mohammad E. Hassona ${ }^{(2)}$ \\ ${ }^{(1)}$ Radiation Sciences Department, Medical Research Institute, Alexandria University, ${ }^{(1)}$ Urology Department, \\ Faculty of Medicine, Alexandia University
}

\section{ABSTRACT:}

Background: Determination of tumor markers in body fluids lining the tumor should provide more reliable information on the malignancy, since dilution, metabolism and execration have very limited, if any, effect on the actual marker concentration, which makes urine the ideal candidate for bladder malignancies.

The present work aimed to evaluate the role of Tumor-Associated Trypsin Inhibitor (TATI), Cytokeratin Fragment Antigen (CYFRA) 21.1, Nuclear Matrix Protein 22 (NMP-22) and Tumor PolypeptideSpecific (TPS) Antigen in urine as potential diagnostic and prognostic markers for bladder cancer, in relation to urine cytology.

The study included 3 groups. Group 1 comprised of 60 patients with primary bladder cancer, group 2 composed of 40 patients with benign urologic diseases and group 3 included 40 healthy volunteers of matching age and sex as a control group. From each subject, one random midstream urine sample was collected before endoscopy. TATI, CYFRA 21.1 and TPS were assayed by radioimmunomertry while NMP-22 was assayed by ELISA. Patients were followed up for 36 months.

Mean levels of all measured parameters were significantly higher in bladder cancer group than those in benign and control groups. ROC curves showed that they were all of diagnostic significance, and at cutoff values of $42 \mu \mathrm{g} / \mathrm{g} \mathrm{cr}, 21 \mu \mathrm{g} / \mathrm{g} \mathrm{cr}, 10.5 \mathrm{U} / \mathrm{g}$ cr and $152 \mathrm{IU} / \mathrm{g} \mathrm{cr}$; respectively, TATI, CYFRA 21.1, NMP-22 and TPS had sensitivities of $82.0 \%, 80.4 \%, 73.9 \%$ and $68.2 \%$ and specificities of $80.5 \%, 73.1 \%$, $72.4 \%$ and $61.5 \%$; respectively. Patients with elevated initial levels of markers at presentation than their respective cutoff values had significantly lower disease-free survival (DFS), also DFS decreased as the number of positive markers increased.

In bladder cancer patients, initial urinary levels of TATI, CYFRA 21.1, NMP-22 and TPS at presentation were significant diagnostic markers with acceptable sensitivities and specificities, and also were significant prognostic markers. When these four markers were joined, DFS declined as the number of positive markers increased.

\section{INTRODUCTION}

Bladder cancer has always received much attentiveness in Egypt due to its high prevalence and high mortality rates. In males, incidence rates of bladder cancer are among the highest in the world, thus in males, it is the first site of cancer incidence while it is the second in females. Also the mortality rates resulting from bladder malignancies in Egypt are the highest in the world. (1) Egypt's world-standardized incidence was 37/100,000 for bladder cancer, interpreted as approximately 30,000 new cases per year. ${ }^{(2)}$

Despite treatment, $50 \%$ to $70 \%$ of superficial bladder tumors recur within 5 years after initial resection, while within 2 years, $50 \%$ of patients with muscle-invasive cancer develop distant metastasis, and $60 \%$ die during 5 years, therefore, long-term follow-up is mandatory. ${ }^{(3)}$

Flexible cystoscopy was a more acceptable diagnostic procedure, yet, the procedure remains uncomfortable, expensive and causes urinary tract infections in $16 \%$ of patients, in addition, it overlooks microscopic disease. Urine cytology, which detects cancer cells shed in urine, is non-invasive and easy to perform but its diagnostic sensitivity remains disappointing, especially in low grade cancers. ${ }^{(4)}$

Determination of tumor markers in body fluids lining the tumor should provide more reliable information on the malignancy, since dilution, metabolism and excretion have very limited, if any, effect on the actual marker concentration, which makes urine the ideal candidate for evaluation of markers of bladder malignancies. Several new markers have lately been suggested to improve the diagnostic and 
prognostic sensitivity in urine, so they would have the potential of serving as an adjunct or even an alternate for cystoscopy. ${ }^{(5,6)}$

Tumor-Associated Trypsin Inhibitor (TATI) is a $6-\mathrm{kDa}$ peptide that inhibits trypsin and acrosin and was found identical to the pancreatic secretory trypsin inhibitor. Elevated TATI levels were found in serum and urine of patients with many types of cancer at advanced stages ${ }^{.(7)}$ TATI expression was found to be restricted to superficial cells of normal bladder urothelium but increased expression was noted in both dysplastic mucosa and invasive foci of bladder tumors. TATI gene up-regulation was involved in early urothelial tumor development. ${ }^{(8)}$

The Cytokeratin Fragment Antigen (CYFRA) 21 is a fragment of cytokeratin (CK) 19. CKs are the main structural units of the cytoskeleton of epithelial cells and $20 \mathrm{CK}$ have been classified into 2 types, CKs 1-8 as type II, and CKs 9-20 as type I. Microfilaments are heteropolymers constructed of type I and II keratins, and constitute the cytoskeleton. CK19 is a soluble type I CK with the least molecular mass $(40 \mathrm{kDa})$ among all CKs. The CK expression patterns in tissues are well-preserved even during the transformation process from normal to tumor tissue. (9) CK19 degradation is accelerated in neoplastic epithelial cells due to enhanced protease activity of caspase 3 , a regulator of the apoptosis cascade, and fragments are discharged into blood, resulting in increased serum CYFRA 21.1 values ${ }^{\cdot(10)}$

The nuclear matrix protein-22 (NMP-22) is also identified as nuclear mitotic apparatus protein (NUMA-1). NMP-22 supports the structure of the nucleus and ensures the correct separation of genetic material during mitosis into the respective daughter cells through mitotic spindle stabilization. NMP22 is elevated up to 80 -fold in tumor cells within the urinary tract. NMP22 is shed into the urine due to cellular apoptosis and other mechanisms of tumor cell death ${ }^{(11)}$

Tissue Polypeptide-Specific (TPS) Antigen closely relates to human cytokeratin 18 , which is a crucial component of the protein cytoskeleton of epithelial cells. TPS is synthesized through late S- to M-phase of the cell cycle, then it is released into the blood or other body fluids. Serum TPS concentration is used as an indicator of the rate of cell division and proliferation, as TPS secretion occurs alongside DNA synthesis, protein synthesis, and cell division. ${ }^{(12)}$

In the present study, we evaluated the role of TumorAssociated Trypsin Inhibitor (TATI), Cytokeratin Fragment Antigen (CYFRA) 21.1, Nuclear Matrix Protein 22 (NMP22) and Tumor Polypeptide-Specific (TPS) Antigen in urine as potential diagnostic and/or prognostic markers for bladder cancer, in relation to urine cytology.

\section{SUBJECTS AND METHODS}

The study involved 140 individuals distributed to 3 groups. Group 1 comprised of 60 patients with primary bladder cancer, proven histologically, of which 41 had transitional cell carcinoma (TCC) and 19 had squamous cell carcinoma (SCC). Group 2 was composed of 40 patients with benign urologic diseases (18 bladder stones, 11 urolithiasis and 11 kidney stones), and group 3 included 40 healthy volunteers of matching age and sex as the control group.

The study was executed following the endorsement of the local ethical committee and each subject delivered an informed written consent. Sampling was done before endoscopy and tumors were classified according to the TNM criteria, (13) and grade was assigned using the 2016 World Health Organization tumor grading system. ${ }^{(14)}$ All patients underwent cystoscopy, and were followed up for 36 months after surgery for recurrence to evaluate disease-free survival (DFS)

From each subject, one random midstream sample of urine was collected. The collected urine samples underwent centrifugation $\left(3000 \mathrm{rpm}\right.$ for $10 \mathrm{~min}$ at $4^{\circ} \mathrm{C}$ ) and the cleared solution was stored at $-80^{\circ} \mathrm{C}$ until used, while the sediments were immediately used for cytology. One drop of this sediment was placed on a glass slide and a smear was made, which was fixed and stained with Haemotoxylin and Eosin (H\&E) stain then slides were examined for the presence of malignant cells shed from bladder tumor.

The TATI was assayed by radioimmunoassay (Orion Diagnostica, Espoo, Finland). According to the manufacturer's instructions, in antibody coated tubes, $50 \mu \mathrm{l}$ of the sample were incubated with $200 \mu \mathrm{l}$ of $125 \mathrm{I}$ labelled tracer and $200 \mu \mathrm{l}$ antiserum over-night, proceeded by washing the tubes and counting them on gammacounter. $^{(15)}$

The CYFRA 21.1 was assayed using Immunoradiometric kit (SIS Bio International, Schering S.A., France). According to the manufacturer's instructions, $100 \mu \mathrm{l}$ of sample were incubated with $300 \mu 1$ of 125 I Anti-CYFRA 21.1 over night in anti-CYFRA 21.1 coated tubes, proceeded by washing the tubes and counting them on gamma-counter ${ }^{(16)}$

The TPS was measured by TPS®IRMA kit (IDL Biotech AB (publ), Bromma, Sweden) which is an immunoradiometric assay kit. The assay uses beads that were pre-coated with anti-TPS antibodies. According to the manufacturer's instructions, to each tube $100 \mu \mathrm{l}$ of standards or samples, $200 \mu \mathrm{l}$ of TPS®IRMA 125I Tracer and 1 bead were added, tubes were incubated for $2 \mathrm{~h}$ on shaker then aspirated and the beads washed 3 times, then radioactivity was assessed on a gamma counter. ${ }^{(17)}$

The Human Nuclear matrix protein 22 was measured by NMP-22 ELISA Kit (USCN Life Science, Milano, Italy). According to the manufacturer, $100 \mu$ l of the sample were incubated in wells pre-coated with anti-NMP-22 antibodies for $2 \mathrm{hrs}$ at $37^{\circ} \mathrm{C}$. After aspiration, $100 \mu \mathrm{l}$ of Detection Reagent A was incubated for $1 \mathrm{hr}$ at $37^{\circ} \mathrm{C}$, after aspiration, $100 \mu$ l of Detection Reagent B was incubated for $1 \mathrm{hr}$ at $37^{\circ} \mathrm{C}$. After aspiration, $90 \mu \mathrm{l}$ of Substrate solution was incubated for $30 \mathrm{~min}$. at $37^{\circ} \mathrm{C}$. $50 \mu \mathrm{l}$ of stop solution were added and OD was measured at $450 \mathrm{~nm} .{ }^{(18)}$

Urine creatinine was measured in 24-hr urine, and all measured parameters were related to the measured creatinine excretion. 


\section{STATISTICAL ANALYSIS}

The results of the studied parameters were expressed as Mean \pm Standard Deviation $(\mathrm{M} \pm \mathrm{SD})$. Significance of difference between means was assessed by analysis of variance (ANOVA). Probability (p) was then obtained to ascertain whether the difference between the two groups is statistically significant. Association between clinical and pathological aspects and the measured markers was done by Mann-Whitney U test. All tests were two-sided, and the significance level was set to $\mathrm{p}$ values $<0.05$. Sensitivity, specificity and cutoff values were obtained by Receiver Operating Characteristics (ROC) curve. Survival curves were constructed by the Kaplan-Meier method. Multivariate survival analyses were performed by Cox regression. Statistical end points were cancer-specific and progression-free survival measured from the date of operation to the date of death, relapse, or latest follow-up. All statistical analyses were done by the Statistical Package for Social Sciences software (SPSS version22.0; SPSS Inc.; Chicago, IL, USA).(19)

\section{RESULTS}

The study included 140 individuals in 3 groups. Group 1 consisted of 60 bladder cancer patients (median age 56.9 years; range 40-71 years), Group 2 consisted of 40 patients with benign urologic diseases (median age 57.3years; range 42-73 years), and group 3 included 40 healthy volunteers (median age 56.7years; range 44-72 years) as a control group.

Of the bladder cancer patients, 41 (68.3\%) had transitional cell carcinoma (TCC) and 19 (31.7\%) had squamous cell carcinoma (SCC). The majority of patients were of clinical stage T2 $(41.7 \%)$ and the remaining were of stages $\mathrm{Ta}(8.3 \%), \mathrm{T} 1(21.7 \%)$ and $\mathrm{T} 3(28.3 \%)$. The tumor size ranged from 1.8 to $14.6 \mathrm{~cm}$, with a mean and SD of $8.9 \pm 7.5 \mathrm{~cm}$. Only 13 patients $(21.7 \%)$ had lymph node invasion at diagnosis and only $53.3 \%$ of patients were positive for urine cytology. After 36 months of follow up, 26 patients $(43.3 \%)$ relapsed while 34 patients $(56.7 \%)$ remained cancer-free, table 1.

Table 1: Characteristics of the studies cancer tissues.

\begin{tabular}{ccc}
\hline Clinical parameter & No. & \% \\
\hline Type of bladder cancer & & 68.3 \\
TCC & 41 & 31.7 \\
SCC & 19 & 38.3 \\
\hline Tumor grade & 23 & 61.7 \\
Low-grade & 37 & 8.3 \\
High-grade & 5 & 21.7 \\
\hline Stage $\quad$ & 13 & 41.7 \\
Ta & 25 & 28.3 \\
T2 & 17 & 78.3 \\
T3 & & 21.7 \\
\hline Lymph node invasion & 47 & 53.3 \\
N1 & 13 & 46.7 \\
\hline Urine Cytology & 32 & 56.7 \\
Positive & 28 & 43.3 \\
\hline Negative & & \\
\hline Risease Free Survival (DSF) & 34 & 26 \\
Relapse-free & & \\
\hline
\end{tabular}

For all subjects involved in the study, TATI, CYFRA 21.1, TPS and NMP 22 were measured in urine samples. The mean levels and standard deviation (SD) were presented in table 2. Urinary TATI levels in $\mu \mathrm{g} / \mathrm{g}$ creatinine $(\mathrm{cr})$ were $22.3 \pm 18.4$ for controls, $31.7 \pm 19.1$ for benign subjects and $78.1 \pm 61.3$ in bladder cancer patients. CYFRA 21.1 levels in urine in $\mu \mathrm{g} / \mathrm{g}$ cr were 5.3 \pm 1.5 in controls, $19.6 \pm 14.9$ in benign subjects and $54.4 \pm$ 26.9 in bladder cancer patients. TPS levels in urine in IU/g cr were $44.3 \pm 16.8$ in controls, $72.1 \pm 33.5$ in benign subjects and $162.7 \pm 76.4$ in bladder cancer patients. Urinary NMP 22 levels in U/g cr were $7.5 \pm 4.6$ for controls, $11.2 \pm 6.4$ for benign subjects and $19.8 \pm 7.3$ in bladder cancer patients.

Regarding all biochemical markers investigated, benign levels were significantly higher than control levels and mean levels in bladder cancer patients were significantly higher than mean levels in both control and benign subjects. The difference between mean levels of TCC and SCC patients was not significant in all the parameters measured.

As for the association of the biochemical markers with tumor pathology, as presented in table 3, higher TPS levels were significantly associated with higher tumor grade $(p=0.025)$, higher clinical stage $(p=0.001)$, larger tumor size $(\mathrm{p}=0.031), \mathrm{LN}$ invasion $(\mathrm{p}=0.002)$, positive cytology $(\mathrm{p}=0.005)$ and lower DFS $(\mathrm{p}=0.001)$. High levels of TATI were significantly associated with higher clinical stage $(p=0.014), \quad L N$ invasion $(p=0.037)$, positive cytology $(\mathrm{p}=0.001)$ and lower DFS $(\mathrm{p}=0.001)$. High levels of CYFRA 21.1 and NMP-22 showed significant association only with positive cytology $(\mathrm{p}=0.027$ and0.042) and lower DFS ( $\mathrm{p}=0.021$ and0.008). 
Table 2: Urinary levels ofs TATI, CYFRA 21.1, TPS and NMP 22 (presented as mean \pm SD).

\begin{tabular}{|c|c|c|c|c|c|}
\hline \multirow{2}{*}{ Parameter } & \multirow{2}{*}{$\mathbf{N}$} & \multirow{2}{*}{ Urinary levels } & \multicolumn{3}{|c|}{ P value } \\
\hline & & & p1 & p2 & p3 \\
\hline \multicolumn{6}{|l|}{ TATI ( $\mu \mathrm{g} / \mathrm{g}$ creatinine) } \\
\hline Control & 40 & $22.3 \pm 18.4$ & & & \multirow{5}{*}{0.825} \\
\hline Benign & 40 & $31.7 \pm 19.1$ & $0.012^{*}$ & & \\
\hline Bladder Cancer & 60 & $78.1 \pm 61.3$ & $0.001^{*}$ & $0.037^{*}$ & \\
\hline TCC & 41 & $77.5 \pm 52.8$ & $0.015^{*}$ & $0.041^{*}$ & \\
\hline SCC & 19 & $82.0 \pm 66.1$ & $0.009^{*}$ & $0.042^{*}$ & \\
\hline \multicolumn{6}{|c|}{ CYFRA 21.1 ( $\mu \mathrm{g} / \mathrm{g}$ creatinine $)$} \\
\hline Control & 40 & $5.3 \pm 1.5$ & & & \multirow{5}{*}{0.996} \\
\hline Benign & 40 & $19.6 \pm 14.9$ & $0.025^{*}$ & & \\
\hline Bladder Cancer & 60 & $54.4 \pm 26.9$ & $0.001^{*}$ & $0.024^{*}$ & \\
\hline TCC & 41 & $52.8 \pm 26.8$ & $0.001^{*}$ & $0.033^{*}$ & \\
\hline SCC & 19 & $55.8 \pm 27.0$ & $0.001^{*}$ & $0.030^{*}$ & \\
\hline \multicolumn{6}{|l|}{ TPS (IU/g creatinine) } \\
\hline Control & 40 & $44.3 \pm 16.8$ & & & \multirow{5}{*}{0.967} \\
\hline Benign & 40 & $72.1 \pm 33.5$ & $0.043^{*}$ & & \\
\hline Bladder Cancer & 60 & $162.7 \pm 76.4$ & $0.005^{*}$ & $0.011^{*}$ & \\
\hline TCC & 41 & $162.3 \pm 77.0$ & $0.011^{*}$ & $0.024^{*}$ & \\
\hline SCC & 19 & $162.8 \pm 75.7$ & $0.008^{*}$ & $0.029^{*}$ & \\
\hline \multicolumn{6}{|l|}{ NMP 22 (U/g creatinine) } \\
\hline Control & 40 & $7.5 \pm 4.6$ & & & \multirow{5}{*}{0.826} \\
\hline Benign & 40 & $11.2 \pm 6.4$ & $0.038^{*}$ & & \\
\hline Bladder Cancer & 60 & $19.8 \pm 7.3$ & $0.007^{*}$ & $0.037^{*}$ & \\
\hline TCC & 41 & $19.5 \pm 6.7$ & $0.021^{*}$ & $0.042^{*}$ & \\
\hline SCC & 19 & $17.88 \pm 7.1$ & $0.028^{*}$ & $0.046^{*}$ & \\
\hline $\begin{array}{l}\rho \text { is considered signi } \\
: \text { significance when } \\
: \text { significance when } \\
: \text { significance when }\end{array}$ & $\begin{array}{l}\text { be } \\
\text { SCC }\end{array}$ & $\begin{array}{l}\text { control levels. } \\
\text { ls. }\end{array}$ & & & \\
\hline
\end{tabular}

Table 3: Association of clinical and tumor pathological parameters with urinary levels of measured biochemical markers in bladder cancer patients.

\begin{tabular}{|c|c|c|c|c|c|}
\hline & & $\begin{array}{c}\text { TATI } \\
\mu \mathrm{g} / \mathrm{g} \text { creatinine }\end{array}$ & $\begin{array}{c}\text { CYFRA 21.1 } \\
\mu \mathrm{g} / \mathrm{g} \text { creatinine }\end{array}$ & $\begin{array}{c}\text { NMP 22 } \\
\text { U/g creatinine }\end{array}$ & $\begin{array}{c}\text { TPS } \\
\text { IU/g creatinine }\end{array}$ \\
\hline \multicolumn{6}{|c|}{ Tumor Grade } \\
\hline & Low-grade $(n=23)$ & $64.4 \pm 50.7$ & $45.7 \pm 24.2$ & $18.4 \pm 7.2$ & $84.3 \pm 42.7$ \\
\hline & High-grade $(n=37)$ & $87.3 \pm 61.8$ & $64.9 \pm 29.8$ & $20.0 \pm 7.5$ & $232.5 \pm 115.3$ \\
\hline p & & 0.082 & 0.134 & 0.653 & $\mathbf{0 . 0 2 5}^{*}$ \\
\hline \multicolumn{6}{|l|}{ Stage } \\
\hline & $\mathrm{Ta} / 1 \quad(n=18)$ & $53.7 \pm 37.9$ & $43.5 \pm 26.7$ & $17.3 \pm 7.7$ & $81.4 \pm 37.2$ \\
\hline & $T 2 / 3(n=42)$ & $111.5 \pm 69.7$ & $65.3 \pm 30.5$ & $21.8 \pm 6.0$ & $233.6 \pm 101.8$ \\
\hline p & & $0.014^{*}$ & 0.158 & 0.130 & $\mathrm{O.001}^{*}$ \\
\hline \multicolumn{6}{|c|}{ Tumor size } \\
\hline & $<5 \mathrm{~cm} \quad(\mathrm{n}=21)$ & $75.4 \pm 56.2$ & $51.7 \pm 26.9$ & $16.7 \pm 6.3$ & $96.2 \pm 44.6$ \\
\hline & $\geq 5 \mathrm{~cm}(\mathrm{n}=39)$ & $88.3 \pm 67.9$ & $56.1 \pm 25.2$ & $22.1 \pm 7.9$ & $221.3 \pm 89.7$ \\
\hline $\mathbf{p}$ & & 0.651 & 0.734 & 0.217 & $0.031^{*}$ \\
\hline \multicolumn{6}{|c|}{ LN invasion } \\
\hline & -ve $(n=47)$ & $55.3 \pm 45.9$ & $49.5 \pm 27.5$ & $14.7 \pm 7.3$ & $79.4 \pm 47.0$ \\
\hline & $+v e(n=13)$ & $100.7 \pm 71.1$ & $56.9 \pm 29.2$ & $23.7 \pm 9.1$ & $240.3 \pm 104.1$ \\
\hline $\mathbf{p}$ & & $0.037^{*}$ & 0.218 & 0.086 & $0.002^{*}$ \\
\hline \multicolumn{6}{|c|}{ Cytology } \\
\hline & -ve $(n=28)$ & $43.8 \pm 31.3$ & $38.5 \pm 24.2$ & $12.9 \pm 6.7$ & $77.6 \pm 49.3$ \\
\hline & $+v e(n=32)$ & $108.7 \pm 77.1$ & $75.4 \pm 29.6$ & $23.1 \pm 8.9$ & $238.3 \pm 108.7$ \\
\hline p & & $0.001^{*}$ & $0.027^{*}$ & $\mathbf{0 . 0 4 2}^{*}$ & $\mathbf{0 . 0 0 5}^{*}$ \\
\hline \multicolumn{6}{|l|}{ DFS } \\
\hline & Relapse-free $(n=34)$ & $45.7 \pm 32.7$ & $35.7 \pm 25.5$ & $12.2 \pm 5.3$ & $75.4 \pm 42.7$ \\
\hline & Relapsed (n=26) & $105.5 \pm 78.5$ & $75.7 \pm 31.2$ & $24.6 \pm 9.5$ & $243.1 \pm 88.1$ \\
\hline p & & $0.001^{*}$ & $0.021^{*}$ & $\mathbf{0 . 0 0 8}^{*}$ & $\mathbf{0 . 0 0 1}^{*}$ \\
\hline
\end{tabular}

: Mann-Whitney $U$ test, the test is considered significant when $\mathrm{p} \leq 0.05$. 
To set cutoffs for the studied parameters as diagnostic markers, ROC curves were established as shown in figure 1 and table 4 . All biochemical markers were statistically significant $(0.011, .018,0.027$ and 0.032 for TATI, CYFRA 21.1, NMP 22 and TPS; respectively). The highest AUC, 0.83, was found for TATI, which at a cutoff value of $42 \mu \mathrm{g} / \mathrm{g}$ cr showed a sensitivity of $82.0 \%$ and specificity of $80.5 \%$. CYFRA 21.1 was also a good marker for bladder cancer with AUC of 0.81 , and at a $21.0 \mu \mathrm{g} / \mathrm{g}$ cr cutoff value, it showed $80.4 \%$ sensitivity and $73.1 \%$ specificity. Followed by NMP 22 with an AUC of 0.78 at a cutoff level of $10.5 \mathrm{U} / \mathrm{g}$ cr with a sensitivity and specificity of $73.9 \%$ and $72.4 \%$; respectively. TPS had the least AUC of 0.75 and at a cutoff value of $152 \mathrm{IU} / \mathrm{g}$ cr, its sensitivity and specificity were $68.2 \%$ and $61.5 \%$; respectively

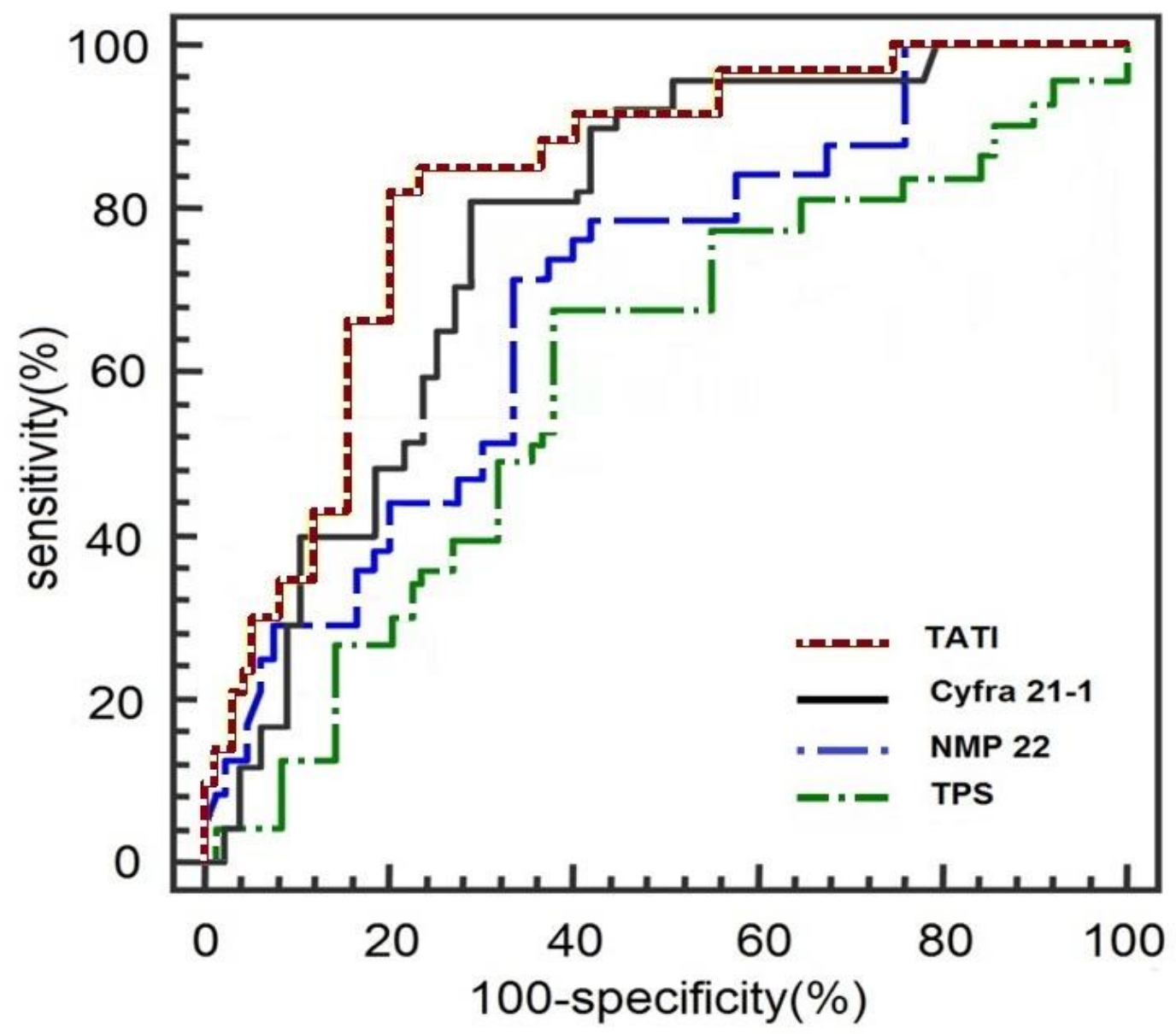

Figure 1: ROC curve for urinary levels of studied urinary markers.

Table 4: AUC, optimum cutoff, sensitivity and specificity of urinary TATI, CYFRA 21.1, NMP 22 and TPS for the detection of bladder cancer.

\begin{tabular}{|c|c|c|c|c|}
\hline $\begin{array}{ll}\text { value } & \text { Parameter } \\
\end{array}$ & TATI & CYFRA 21.1 & NMP 22 & TPS \\
\hline $\mathbf{p}$ & 0.011 & 0.018 & 0.027 & 0.032 \\
\hline AUC & 0.83 & 0.81 & 0.78 & 0.75 \\
\hline Cut off & $42 \mu \mathrm{g} / \mathrm{g} \mathrm{cr}$ & $21 \mu \mathrm{g} / \mathrm{g} \mathrm{cr}$ & $10.5 \mathrm{U} / \mathrm{g} \mathrm{cr}$ & $152 \mathrm{IU} / \mathrm{g} \mathrm{cr}$ \\
\hline Sensitivity (\%) & 82.0 & 80.4 & 73.9 & 68.2 \\
\hline Specificity (\%) & 80.5 & 73.1 & 72.4 & 61.5 \\
\hline
\end{tabular}

VALUE OF BIOCHEMICAL URINARY MARKERS IN DIAGNOSIS AND PROGNOSIS OF BLADDER CANCER PATIENTS 

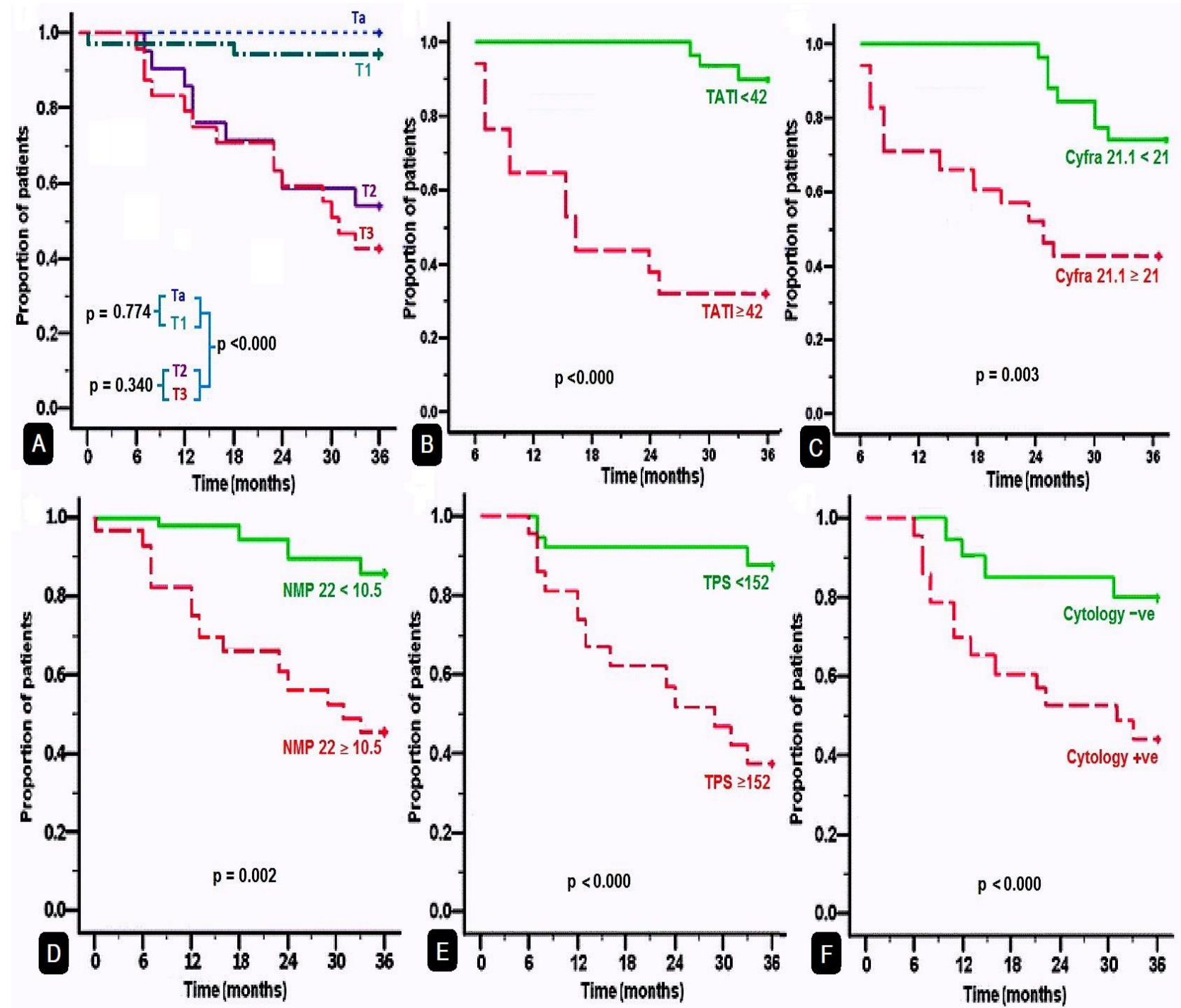

Figure 2: Kaplan-Meier Survival curves of all patients according to; A: stage; B: TATI; C: CYFRA 21.1; D: NMP 22; E: TPS; and F: cytology.

After 36 months of follow up, these cut offs for all parameters were used to establish Kaplan-Meier survival curves according to disease stage, TATI, CYFRA 21.1, NMP 22, TPS and urine cytology. All parameters were significant factors for survival, as presented in figure 2 . Stage was a significant variable in DFS ( $\mathrm{p}=0.000)$, as patients with low stage showed higher survival (35 months) than patients with high stage (21 months). As for TATI, patients with initial TATI levels $<42 \mu \mathrm{g} / \mathrm{g}$ cr had significantly higher survival $(\mathrm{p}=0.000)$ than patients with TATI levels $\geq 42 \mu \mathrm{g} / \mathrm{g}$ cr $(31.5$ vs 17.3 months; respectively). Also patients with CYFRA $21.1<21 \mu \mathrm{g} / \mathrm{g}$ cr showed higher survival (29.8 months) than patients with CYFRA $21.1 \geq 21 \mu \mathrm{g} / \mathrm{g}$ cr (19.4 months), and the difference was significant $(\mathrm{p}=0.003)$. The same was noted for NMP 22, where a significant difference $(\mathrm{p}=0.002)$ existed between patients with NMP $22<10.5 \mathrm{U} / \mathrm{g}$ cr $(32.1$ months) and patients with NMP $22 \geq 10.5 \mathrm{U} / \mathrm{g}$ cr $(23.3$ months). Patients with TPS $<152 \mathrm{IU} / \mathrm{g}$ cr showed a significantly higher survival (30.8 months) than patients with TPS $\geq 152 \mathrm{IU} / \mathrm{g}$ cr $(16.7$ months $)$ with $\mathrm{p}=0.000$. A significant difference $(\mathrm{p}=0.000)$ also existed between patients with negative cytology (24.0 months) and patients with positive cytology (17.8 months).

Table 5 showed that the presence of more than one elevated marker strongly affected survival. Patients with 2 $(p=0.017), 3(p<0.001)$ or $4(p<0.001)$ elevated markers had significantly lower survival rate compared to patients with no or $1 \quad(p=0.265)$ elevated marker. Survival rate showed a gradual decrease as the number of elevated markers increased. The addition of cytology di 21 improve the diagnostic or prognostic performance ( 21 of the makers under evaluation for bladder cancer. The addition of more than one marker did not add to the sensitivity and specificity of the diagnostic accuracy. 
Table 5: Combined effects of the elevated urinary biochemical markers on disease-free survival of bladder cancer patients.

\begin{tabular}{llll}
\hline No. of elevated markers & No. of patients $(\%)$ & DFS rate & P1 \\
\hline 0 & $6(10.0 \%)$ & $83.3 \%$ & - \\
1 & $19(31.7 \%)$ & $78.9 \%$ & 0.265 \\
2 & $16(26.7 \%)$ & $56.3 \%$ & 0.017 \\
3 & $12(20.0 \%)$ & $25.0 \%$ & $<0.001$ \\
4 & $7(11.6 \%)$ & $28.6 \%$ & $<0.001$ \\
\hline P2 & & $<0.001$ & \\
\hline
\end{tabular}

P1 significance when compared to 0 .

P2 significance of trend among all groups.

\section{DISCUSSION}

Preliminary clinical diagnosis of bladder cancer relies predominantly on cystoscopy along with urine cytology. Cystoscopy is an uncomfortable and costly invasive procedure that may require anesthesia of the patient and entails the risk of urinary tract infection. The technique enables visualization of the bladder lining and biopsy of suspicious lesions for histopathological diagnosis and staging, but it often fails to detect in-situ neoplasm. Evaluation by cytology depends upon microscopic visualization of shed cancer cells in voided urine The technique delivers good results in high-grade and high-stage tumors, but because Ta and T1 tumors shed very few cancer cells into the urine, the sensitivity of urine cytology for earlystage tumors is low, ranging only $20-40 \%$. Coupled with the fact that cytology is prone to inter-observer variation, it is understandably not considered as a standalone test for application in a potential bladder cancer clinical investigation. $^{(20)}$

After initial treatment of bladder cancer, patients are continuously surveillanced by cystoscopy and cytology done routinely in order to achieve early detection of new tumor development. Consequently, the advent of non-invasive assays that could diminish the need for cystoscopy would be of extreme benefit to both patients and the healthcare system. For bladder cancer, the ease of access of urine samples is considered a principal advantage, as sample can be non-invasively obtained, avoiding patient discomfort and complications, ample amounts of sample could be obtained for analysis and repeat sampling is easily achievable. ${ }^{(21)}$

Thus far, no single marker was identified that can guide in the surveillance of bladder cancer and minimize the frequency of cystoscopy, but combining these markers may enhance their reliability; however, it may augment the costs. ${ }^{(22)}$ In the current study a panel of four urinary markers (TATI, NMP 22, CYFRA 21.1 and TPS) were used in addition to urine cytology for detecting primary bladder cancer and predicting its recurrence.

In the current study, TATI levels in bladder cancer patients were found significantly higher than both benign and control levels. The ROC curve showed that TATI had an excellent diagnostic significance with an optimum cutoff value of $42 \mu \mathrm{g} / \mathrm{g} \mathrm{cr}$, sensitivity of $82.0 \%$ and specificity of $80.5 \%$. Initially higher
TATI levels showed a significant association with higher stage and $\mathrm{LN}$ involvement. Concerning survival, patients with initial TATI $<42 \mu \mathrm{g} / \mathrm{g}$ cr had a significantly better DFS than those with $\mathrm{TATI} \geq 42 \mu \mathrm{g} / \mathrm{g}$ cr

Because of the discrepancy of results, our results were conforming to some studies and contradictory to others. In accordance with our results, Kelloniemi et al. ${ }^{(23)}$ found that higher TATI levels in urine were associated with muscleinvasive disease at diagnosis and decreased survival in patients with superficial and invasive bladder cancer. Shariat et al. ${ }^{(24)}$ and Patschan et al., ${ }^{(25)}$ reinforced this conclusion, demonstrating that patients with invasive tumor had greater TATI levels than those with superficial, non-invasive disease; however, no significant correlation was found with tumor grade. Another study exhibited that TATI was efficient in monitoring disease activity and response to treatment in patients with advanced and metastatic bladder cancer. ${ }^{(26)}$ In contrast, Hotakainen et al. ${ }^{(27)}$ have shown that TATI expression decreases with increasing tumor stage and grade. While Gkialas et al., ${ }^{(28)}$ found TATI to be a valuable urinary marker but was not correlated with tumor stage.

In the current study, CYFRA 21.1 urinary levels in bladder cancer patients were statistically higher than that in both benign and control levels. Regarding diagnostic value, CYFRA 21.1 had an excellent diagnostic significance with an optimum cutoff value of $21 \mu \mathrm{g} / \mathrm{g} \mathrm{cr}$, sensitivity of $80.4 \%$ and specificity of $73.1 \%$. Initially higher CYFRA 21.1 levels were not associated with clinicopathlogical features. As for survival, patients with initial urinary CYFRA 21.1 level $<21 \mu \mathrm{g} / \mathrm{g}$ cr had a significantly better DFS than those with CYFRA $21.1 \geq 21 \mu \mathrm{g} / \mathrm{g} \mathrm{cr}$.

Several studies and meta-analyses have reported that bladder cancer patients had higher CYFRA 21.1 levels than healthy subjects. ${ }^{(9,10,28-31)}$ This result suggested that CYFRA 21.1 levels are a competent biomarker for diagnosing bladder cancer. In addition, CYFRA 21.1 values in patients having various stages of bladder cancer were not significantly different. Thus, it is necessary to develop additional urinary biomarkers for the differential diagnosis of stage I, II and III bladder cancer. ${ }^{(9,10,28-}$ ${ }^{31)}$ However, contradictory results have been reported specially that its application as a surveillance tool for superficial bladder carcinoma was not very useful, because urinary assessment of CYFRA 21.1 showed low sensitivity for recurrent disease. ${ }^{(32,33)}$ Discrepancy of data reported is most probably attributed to

VALUE OF BIOCHEMICAL URINARY MARKERS IN DIAGNOSIS AND PROGNOSIS OF BLADDER CANCER PATIENTS 
various methods of detection and different cutoff levels used. To our knowledge, the prognostic power of preoperative evaluation of CYFRA 21.1 in urine has not been reported previously.

sOur results indicated that NMP-22 levels in urine of bladder cancer patients were significantly higher than that in both benign and control levels. As a diagnostic marker, NMP-22 had a good diagnostic significance with an optimum cutoff value of 10.5 $\mathrm{U} / \mathrm{g}$ cr, sensitivity of $73.9 \%$ and specificity of $72.4 \%$. Initially higher NMP-22 levels was not significantly associated with tumor pathology of patients, but it showed only a significant association with urine cytology. Concerning survival, patients with initial NMP-22<10.5 U/g cr had significantly better DFS than those with NMP- $22 \geq 10.5 \mathrm{U} / \mathrm{g}$ cr.

NMP-22 is expressed specifically in urinary tract transitional cells. ${ }^{(34)}$ Typically, patients with TCC are expected to have higher concentration of NMP-22 in their urine than patients with SCC, but that was not the case in the current study, where no significant difference was noted in NMP-22 urinary levels between TCC and SCC. Although previous reports all demonstrated the validity of NMP-22 as a diagnostic bladder cancer test, the sensitivities and specificities varied widely depending on the cutoffs used in each study. Sensitivities ranged from $47 \%$ to $100 \%$ and specificities ranged from $55 \%$ to $98 \%$. (11,34-35) A meta-analysis of 24 studies ${ }^{(36)}$ showed that at a cutoff value of $10 \mathrm{U} / \mathrm{ml}$ the sensitivity of NMP-22 test was $71 \%$ and the specificity was $80 \%$, these data were in consensus with our results.

The current results showed that urinary TPS levels in bladder cancer patients were significantly higher than that in both benign and control levels. For diagnosis, ROC curve showed that TPS had a good diagnostic significance and at the optimum cutoff value of $152 \mathrm{IU} / \mathrm{g} \mathrm{cr}$, sensitivity was $68.2 \%$ and specificity was $61.5 \%$. Most of previous reports demonstrated the diagnostic potential of TPS for bladder cancer, the sensitivities and specificities varied widely depending on the cutoffs used in each study. Sensitivities ranged from $34.6 \%$ to $73.1 \%$ and specificities ranged from $50 \%$ to $88.4 \% .^{(12,37-38)}$

Interestingly, initially higher TPS levels were significantly associated with most of the clinicopathological parameters as higher tumor size, grade, stage and lymph node involvement. Contradictory results were reported regarding correlation with clinicopathological features where some reported positive correlation with some clinicopathlogical parameters ${ }^{(37,39)}$, others found no correlation with any of them. ${ }^{(38)}$ As regard survival, our patients with initial TPS $<152 \mathrm{IU} / \mathrm{g}$ cr had significantly better survival than those with TPS $\geq 152 \mathrm{IU} / \mathrm{g}$ cr.

Most published studies used serial measurements of urinary markers to follow up bladder cancer patients, but very few studies directly investigated the association between urinary levels of biomarker at presentation and outcome, with fewer studies investigated if urinary biomarkers may provide prognostic information over and above that provided by typical clinicopathological factors.

The most significant finding of this study was that combined analysis of multiple urinary tumor markers had a much higher potential value in terms of prognostic importance. Bladder cancer patients with higher levels of any of the four studied urinary markers had significantly worse survival, however, when they were combined, DFS decreased as the number of elevated markers increased $(\mathrm{p}<0.0001)$. The most significant drawback of using one of the biochemical markers was that its sensitivity and specificity were not high enough in addition to the overlap with normal or benign levels, but our results suggested that the sensitivity of these markers can be improved significantly if they are used in combination as a panel of markers.

In conclusion, in bladder cancer patients, initial urinary levels of TATI, CYFRA 21.1, NMP-22 and TPS at presentation were significant diagnostic markers with acceptable sensitivities and specificities, and their higher levels were significantly associated with decreased survival. When these four markers were used together, DFS decreased as the number of elevated markers increased.

\section{REFERENCES}

1. Gad El Mawla N, Khaled NH. Bladder cancer in Africa: Update. Semin Oncol 2001; 28: 174-8.

2. Felix AS, Khaled H, Zaghloul MS, et al. The changing patterns of bladder cancer in Egypt over the past 26 years. Cancer Causes Control 2008; 19: 421-9.

3. Shariat SF, Lotan Y, Karakiewizc PI. Critical evaluation of urinary markers for bladder cancer detection and monitoring. Rev Urol 2008; 10: 120-135.

4. McDougal WS, Kaufman DS, Dahl DM, Michaelson MD, Zietman AL. Cancer of the Bladder, Ureter, and Renal Pelvis. $8^{\text {th }}$ ed. Cancer: Principles and practice of oncology, ed. H.S. De Vita VT, Rosenberg SA. Lippincott Williams \& Wilkins. 2008.

5. Coleman JF. Utility of diagnostic and prognostic markers in urothelial carcinoma of the bladder. Adv Anat Pathol 2009; 16: 67-78.

6. Goodison S, Urquidi V. Urinary proteomic profiling for diagnostic bladder cancer biomarkers. Expert Rev Proteomics 2009; 6: 507-14.

7. Huhtala ML, Pesonen K, Kalkkinen N, et al. Purifi cation and characterization of a tumor-associated trypsin inhibitor from the urine of a patient with ovarian cancer. J Biol Chem. 1982; 257: 13713-6.

8. Stenman UH. Role of the tumor-associated trypsin inhibitor SPINK1 in cancer development. Asian J Androl 2011; 13: 628-9.

9. Huang YL, Chen J, Yan W, et al. Diagnostic accuracy of cytokeratin-19 fragment (CYFRA 21.1) for bladder cancer: a systematic review and meta-analysis. Tumour Biol 2015; 36: 3137-45.

10. Dohmoto K, Hojo S, Fujita J, Yang Y, et al. The role of caspase 3 in producing cytokeratin 19 fragment (CYFRA21-1) in human lung cancer cell lines. Int J Cancer 2001, 91: 468-73.

11. Miyake M, Goodison S, Giacoia EG, et al. Influencing factors on the NMP-22 urine assay: an experimental model. BMC Urol. 2012; 12: 23.

12. Sánchez-Carbayo M, Urrutia M, González de Buitrago $\mathrm{JM}$, et al. Evaluation of two new urinary tumor markers: bladder tumor fibronectin and cytokeratin 18 for the diagnosis of bladder cancer. Clin Cancer Res 2000; 6: 3585-94.

13. Edge S, Byrd DR, Compton CC, et al. (Eds.) AJCC Cancer Staging Handbook From the AJCC Cancer Staging Manual. Springer-Verlag: New York, Inc. 2010.

14. Humphrey PA, Moch H, Cubilla AL, Ulbright TM, Reuter VE. The 2016 WHO Classification of Tumours of the Urinary System and Male Genital Organs-Part B: Prostate and Bladder Tumours. Eur Urol 2016; 70: 106-19. 
15. Janeiro E, Guimarães J, Stenman UH, et al. Validation and comparison of tumor-associated trypsin inhibitor (TATI) immunoassays.Clin Chim Acta 2012; 413: 1244-8.

16. Pujol JL, Grenier J, Daures JP, et al. Serum fragments of cytokeratin subunit 19 measured by CYFRA 21-1 immunoradiometric assay as a marker of lung cancer. Cancer Res. 1993; 53:1-6.

17. Ahn SK, Moon HG, Ko E, et al. Preoperative serum tissue polypeptide-specific antigen is a valuable prognostic marker in breast cancer. Int J Cancer 2013; 132: 875-81.

18. Mian C, Lodde M, Haitel A, et al. Comparison of the monoclonal UBC-ELISA test and the NMP22 ELISA test for the detection of urothelial cell carcinoma of the bladder. Urology 2000; 55: 223-6.

19. Argyrous G. (ed.) Statistics for Research: With a Guide to SPSS. $3^{\text {rd }}$ ed., SAGE, UK, 2011.

20. Trivedi D, Messing EM. Commentary: the role of cytologic analysis of voided urine in the work-up of asymptomatic microhematuria. BMC Urol 2009; 9: 13.

21. Smith ZL, Guzzo TJ. Urinary markers for bladder cancer. F1000 Prime Rep 2013; 5: 21.

22. Vrooman OPJ, Witjes JA. Urinary markers in bladder cancer. Eur Urol 2008; 53: 909-16.

23. Kelloniemi E, Rintala E, Finne $\mathrm{P}$, et al. Tumorassociated trypsin inhibitor as a prognostic factor during follow-up of bladder cancer. Urology 2003; 62: 249-53.

24. Shariat SF, Herman MP, Casella R, et al. Urinary levels of tumor associated trypsin inhibitor (TATI) in the detection of transitional cell carcinoma of the urinary bladder. Eur Urol 2005; 48: 424-31.

25. Patschan O, Shariat SF, Chade DC, et al. Association of tumor-associated trypsin inhibitor (TATI) expression with molecular markers, pathologic features and clinical outcomes of urothelial carcinoma of the urinary bladder. World J Urol 2012; 30: 785-94.

26. Pectasides D, Bafaloucos D, Antoniou F, et al. TPA, TATI, CEA, AFP, beta-HCG, PSA, SCC and CA 19-9 for monitoring transitional cell carcinoma of the bladder. Am J Clin Oncol 1996; 19: 271-7.

27. Hotakainen K, Bjartell A, Sankila A, et al. Differential expression of trypsinogen and tumor-associated trypsin inhibitor (TATI) in bladder cancer. Int J Oncol 2006; 28: 95-101.
28. Gkialas I, Papadopoulos G, Iordanidou L, et al. Evaluation of urine tumor-associated trypsin inhibitor, CYFRA 21.1, and urinary bladder cancer antigen for detection of high-grade bladder carcinoma. Urology 2008; 72: 1159-63.

29. Morsi MI, Youssef A, Hassouna ME, et al. Telomerase activity, Cytokeratin 20 and Cytokeratin 19 in urine cells of bladder cancer patients. J Egypt Nat Cancer Inst 2005; 17: 1-14.

30. Kuang LI, Song WJ, Qing HM, et al. CYFRA21-1 levels could be a biomarker for bladder cancer: a metaanalysis. Genetics and Molecular Research 2015; 14: 3921-31.

31. Washino S, Hirai M, Matsuzaki, et al. Clinical usefulness of CEA, CA19-9, and CYFRA21-1 as tumor markers for urothelial bladder carcinoma. Urol Int 2011; 87: 420-8.

32. Fatela-Cantillo D, Fernández-Suárez A, Menéndez V, et al. Low utility of CYFRA 21-1 serum levels for diagnosis and follow-up in bladder cancer patients. J Clin Lab Anal 2005; 19:167-71.

33. Fernandez-Gomez J, Rodríguez-Martínez JJ, Barmadah SE, et al. Urinary CYFRA 21.1 is not a useful marker for the detection of recurrences in the follow-up of superficial bladder cancer. Eur Urol 2007; 51:1267-74.

34. Kundal VK, Pandith AA, Hamid A, et al. Role of NMP22 Bladder Check Test in early detection of bladder cancer with recurrence. Asian Pac J Cancer Prev 2010;11: 1279-82.

35. Yafi FA, Brimo F, Steinberg J, et al. Prospective analysis of sensitivity and specificity of urinary cytology and other urinary biomarkers for bladder cancer. Urol Oncol 2015; 33: 66.e25-31.

36. Fu L, Wang R, Yin L, et al. Nuclear matrix protein 22 (NMP22) test in the diagnosis of bladder cancer: a metaanalysis. Int J Clin Exp Med 2016; 9: 7965-75.

37. Boman $H$, Hedelin $H$, Holmäng $S$. Urine tissuepolypeptide-specific antigen (TPS) as a marker for bladder cancer. Scand J Urol Nephrol 2001; 35: 270-4.

38. Sánchez-Carbayo M, Urrutia M, Silva JM, et al. Urinary tissue polypeptide-specific antigen for the diagnosis of bladder cancer. Urology 2000; 55: 526-32.

39. Menendez V, Galan JA, Fernandez-Suarez A, et al. Prognostic value of tissue-polypeptide specific antigen (TPS) in bladder cancer. Anticancer Res 2002; 22: 3713-6. 